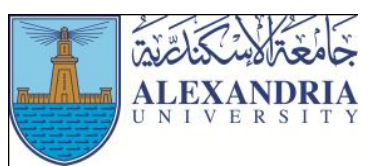

\author{
Journal of Applied Sports Science \\ April 2017, Volume 7, No. 1 \\ www.jass.alexu.edu.eg
}

\title{
Kinetic Analysis for Performance Methods of Long Kick Skill as a Criterion to Select Soccer Goalkeeper
}

\author{
Omar Mohamed Labib Hassan ${ }^{1}$, Mohamed Soliman Mahmoud Husein ${ }^{1}$ \\ ${ }^{1}$ Assistant Professor, Department of Kinesiology, Faculty of Physical Education, Minia University, Egypt
}

\begin{abstract}
Goals: the kinetic analysis of the values of the basic general moment movement variables for the performance for long kick skill of soccer with three method (the whip kick, the rebound kick and simple kick. Design: using the descriptive method by cinematographic analysis. Apparatus: (three) Sony Video Camera of frequency (60 range / sec), A computer with Skill Spector program. Participants: (five) goalkeepers, who were students of Minia university in the age stage (18-20) years. Steps Preliminary measurement in some somatic, physical and age variables and then the main study (video imaging). The statistical treatment: skewness coefficient, kurtosis coefficient. mean square error. Results: the mastery of the whip kick in most general and moment movement variables for various body points following by the rebound kick, then the simple method and the criterions of choosing the soccer goalkeeper according to the kinematic analysis represented in the horizontal distance for flying of soccer. Conclusions: the whip kick method is the best in achieving the horizontal distance of soccer so it is the most suitable one for learning and training programs and the kinetic analysis main means and criterion for the choosing of soccer goalkeeper.
\end{abstract}

Keywords: kinesiology, soccer, goalkeepers, kicking, long kick

\section{Introduction}

$\mathrm{T}$ The mechanical goal of long movement kick for soccer goalkeeper is to achieve or arrive the ball to the furthest horizontal possible distance. This depends on several factors, the most important ones are kick point height of the ball, speed of ball take-off, angle of ball take-off (Talha, 1993, p. 210-212) " argues that run speed, angle of the take - off. and starting point height are the most important movement factors in which projectile whether it is the athlete body or the instrument used in sport as the ball arrival to the furthest horizontal possible distance " The researcher believe that the straight line is the closest road for the goal. So , it is better that the point of ball drop is in front of opponent penalty zone in order to arrive quickly to opponent goal particularly in the case of fast break. The researcher concerned with determining broad angle of ball take-off beside the previous specific three variables (Lotfy \& Yahiya , 2014, p. 13) argue that scoring is more by or through attack or penetration in front of penalty zone than its sides.

Through researcher analysing of the results of the matches of the European Nations Cup in France (2016) found that the average number of long kicks to each goalkeeper per each match was about (15) kicks, (seven) fixed kicks, (eight) movement kicks and all are considered a mean for attacking the opponent, indicating the importance of goalkeeper kicks in making fast break on the opponent particularly if the goalkeeper succeeded in dropping the ball through his long kicks close to the opponent penalty zone and this will make a strong pillar for the succeed attack of the goalkeeper team, intense danger and pressure on the opponent team and perhaps it is a direct reason in scoring and winning the match for the goalkeeper team. They noticed that each goalkeeper uses one method for long moving kick and he doesn't change it and that the majority of goalkeepers uses the simple kick, which perhaps is not better for him that leads the researcher to conduct this study to recognize biomechanics differences of performing long movement kick for a distinctive group of goalkeepers to know important movement attributes and differences in performance and preference order for these kicks for various goalkeepers as a cornerstone for movement learning and training processes in this important field. To achieve his study goals, the researcher uses more than (16) varied 
studies, all concentrated with soccer kicking for team athletes

Hosaam Eldeen, Talha. (1993) . biomechanics . theoretical and applied bases . Cairo : Dar El Feker ELAraby .

Alsayed , Mohamed \& Kamel ,Yahiaa . (2006) . an analytical study for attack tactical movements in the attack third based upon shooting opportunities in soccer . magazine of sport science. VOL . December. 2006.

Garry Gelady . (2014) . Evaluating the ability of goalkeepers in English Premier League football, de GRUYTER, DOI 10.1515/jqas-2014-0004 JQAS 2014; aop.

Jeffrey K. Leela \& Donna M. G. Comissiong . (2009) . Modelling Football Penalty Kicks, The University of the West Indies, St. Augustine, Trinidad. (Received 7 February 2009; accepted $24 \quad$ April 2009) .

Alen Kapidžić1, Tarik Huremović1,\& Alija Biberovic1. (2014) . Kinematic Analysis of the Instep Kick in Youth Soccer Players, Journal of Human Movements volume 42/2014, 81- 90 DOI: 10.2478/hukin- 2014- 0063 Kinesiology Accepted for printing in Journal of Human Movements vol. 42/2014 on September 2014.

other than the goalkeeper, except the study of (Gleady, 2014) that concerned with evaluating goalkeeper ability in English excellent tournament, and (15) other studies including the study of (Jefry k, Lili \& Dona, 2009) about penalty kick, (Kapidžić1, Huremović1 \& Biberovic, 2014 ) about corner kick, and the remaining studies are about free kick, that these studies concerned with fixed kick only and for team athletes other than the goalkeeper that leading him to conduct this study hoping to achieve its desired goals.

The importance of this study represented in Recognizing the details of the Whip kick style (a new method) for football, Preferring between methods of long movement kick for soccer goalkeepers, show the role of long movement kicks as a mean of fast break, Establish a kinetic basis for the selection of football goalkeepers, a scientific addition from where the scarcity of studies of Kinesiology related to analysing the skills of football goalkeepers .

\section{Aim of the Research}

1- Kinetic analysis for values of general and momentary basic movement variables for the research sample performance for the skill of long moving kick, (prepared from the goalkeeper), with the method of whip kick (An innovative method), the method of rebound kick and the method of simple kick and finding difference between values of variables for the three methods.

2- Recognizing the most important basic movement variables which resulted from the kinetic analysis for the skill of long moving kick, (which prepared from the goalkeeper), by the three previous methods as a criterion to select soccer goalkeeper.

\section{Question of the Research}

1- What are the result of the Kinetic analysis for values of general and moment basic movement variables for the research sample performance for the skill of long moving kick, which made from the goalkeeper, with the method of whip kick(An innovative method), the method of rebound kick and the method of simple kick ?

2- What are the most important basic movement variables which resulted from the kinetic analysis for the skill of long moving kick, which made from the goalkeeper, with the three previous methods as a criterion to select soccer goalkeeper?

\section{Methods}

\section{Methodology and Participants:}

The researcher used the descriptive method to a purposive sample of (five) goalkeepers from excellent second class in soccer from Minia university students in the age stage from (18-20) years, Homogeneity was found between them in some age, somatic and physical variables, and (table.1) 
Table (1)

Arithmetic mean, median, standard deviation, skewness coefficient and kurtosis coefficient for the age, somatic and physical variables of the research sample $(n=5)$

\begin{tabular}{|c|c|c|c|c|c|c|c|}
\hline Variables & $\begin{array}{c}\text { Measurement } \\
\text { unit }\end{array}$ & $\begin{array}{c}\text { Measurement } \\
\text { aim }\end{array}$ & $\begin{array}{l}\text { Arithmetic } \\
\text { mean }\end{array}$ & median & $\begin{array}{l}\text { Standard } \\
\text { deviation }\end{array}$ & $\begin{array}{l}\text { Skweness } \\
\text { coefficient }\end{array}$ & $\begin{array}{l}\text { kurtosis } \\
\text { coefficien }\end{array}$ \\
\hline AGE & year & chronological age & 18.40 & 18.40 & 0.90 & 0.00 & 0.41 \\
\hline Weight & $\mathrm{kg}$ & Body weight & 72.00 & 69.00 & 5.05 & 1.78 & 0.71 \\
\hline Total length & c.m & Body length & 178.40 & 178.00 & 4.62 & 0.26 & 1.85 \\
\hline Tilt on the box & c.m & $\begin{array}{l}\text { Prolong the back } \\
\text { muscles of the } \\
\text { body }\end{array}$ & 14.60 & 15.00 & 4.77 & -0.25 & -1.12 \\
\hline $30 \mathrm{~m}$. running & second & Transition speed & 5.44 & 5.44 & 0.33 & 0.00 & -2.61 \\
\hline $\begin{array}{c}\text { Rebound } \\
\text { running }\end{array}$ & second & Agility & 12.20 & 12.35 & 0.69 & 0.65 & 0.09 \\
\hline $\begin{array}{l}\text { Numbered } \\
\text { circles }\end{array}$ & second & Compatibility & 6.63 & 6.71 & 0.44 & 0.55 & 0.61 \\
\hline Broad jump & meter & $\begin{array}{l}\text { The muscular } \\
\text { power of legs }\end{array}$ & 2.21 & 2.15 & 0.19 & 0.95 & -1.38 \\
\hline $\begin{array}{l}\text { Standing on the } \\
\text { beam }\end{array}$ & second & Balance & 14.00 & 13.00 & 2.92 & 1.03 & -1.60 \\
\hline
\end{tabular}

clarifies Values of skewness and kurtosis coefficients for the previous variables of the basic research sample are restricted between $(+3,-3)$ indicating the equality of the research sample distribution in these variables.

\section{Tools of data collection:}

Apparatus : A restameter to measure height, a Balance to measure weight, (three) Sony Video Camera of frequency (60range / sec) with (three) triple stands equipped with a water balance, A computer with Win Analysis program .

Instruments : Stopwatch, a measurement tape of (30) meters, standard unit (a diagram scale), forms for measuring data of trials following up, measuring physical abilities .

Tests: for measuring back muscles and back thighs, transition speed, agility, neuromuscular coordination, balance, legs muscular capability (Hassanin, 1999 , p. $346,381,395,406,425)$ and Test of ball direction competency in performing skills of long kicks (prepared by the researcher) (Appendix 4) .

\section{Administrative steps of the research:}

Preliminary measurement : On 27/04/2016 it was conducted in some age, somatic and physical variables at fencing hall in faculty of physical education, Minia university in purpose of finding distribution normality between the research sample individuals in these variables

The basic study: It was conducted on 03/05/2016 where the research sample was pictured at soccer court in Minia university stadium as much as (three) kicks (trials) for each athlete of the five athletes, the best one was selected for each player, consequently the best five trials were taken for every method that was submitted for kinetic analysis

Hassanin , Mohamed . (1999) . measurement and evaluation in physical education . first section . edition 4. Cairo: Dar El Feker El Araby

then take the arithmetic mean to identify the values of the general, momentary variables of movement between the three performance methods. The study concentrated at the most important kinetic variables for the kinetic performance, based on the results of the kinetic analysis and according to the digital Range of the value of the best Trial and the Mean of total trials or Mean square error between the kinetic variables during the (15) fifteen trial, the researcher have specified the value of mean square error, which is limited to (0-2) as the basis for selection in this study and that the smaller value is the best

\section{Used statistical methods:}

Mean, standard deviation, skewness coefficient, kurtosis coefficient, Mean squared error. 


\section{Results}

Table (2)

General movement variables of the research sample performance for the skill of kicking soccer with the three methods

\begin{tabular}{|c|c|c|c|c|c|c|}
\hline Parts & $\begin{array}{l}\text { Move } \\
\text { varia }\end{array}$ & & $\begin{array}{c}\text { Measurement } \\
\text { unit }\end{array}$ & $\begin{array}{l}\text { Whip } \\
\text { kick }\end{array}$ & $\begin{array}{c}\text { Reboud } \\
\text { kick }\end{array}$ & $\begin{array}{l}\text { Simple } \\
\text { kick }\end{array}$ \\
\hline \multirow{8}{*}{$\begin{array}{l}\text { Total } \\
\text { body }\end{array}$} & \multirow{4}{*}{ Performance time } & Introductory stage & Second & 0.20 & 0.20 & 0.16 \\
\hline & & The primary stage & Second & 0.10 & 0.10 & 0.10 \\
\hline & & Final stage & Second & 0.04 & 0.08 & 0.12 \\
\hline & & Total & Second & 0.34 & 0.38 & 0.38 \\
\hline & \multirow{4}{*}{$\begin{array}{c}\text { Percentage of performance } \\
\text { time }\end{array}$} & Introductory stage & $\%$ & 59 & 0.53 & 42 \\
\hline & & The primary stage & $\%$ & 29 & 0.26 & 26 \\
\hline & & Final stage & $\%$ & 12 & 0.21 & 32 \\
\hline & & Total & $\%$ & 100 & 100 & 100 \\
\hline \multirow{6}{*}{$\begin{array}{l}\text { Kicking } \\
\text { foot }\end{array}$} & \multirow{3}{*}{$\begin{array}{l}\text { Linear displacement of } \\
\text { Simple foot }\end{array}$} & Horizontal X & Meter & 2.03 & 1.70 & 1.68 \\
\hline & & Vertical Y & Meter & 0.63 & 0.87 & 1.06 \\
\hline & & Broad Z & Meter & 0.99 & 0.31 & 0.41 \\
\hline & \multirow{3}{*}{$\begin{array}{l}\text { Intermediate Velocity of } \\
\text { Simple foot }\end{array}$} & Horizontal X & Meter/ sec & 10.15 & 17.00 & 5.60 \\
\hline & & Vertical Y & Meter/ sec & 3.15 & 8.70 & 3.53 \\
\hline & & Broad Z & Meter/ sec & 4.95 & 3.10 & 1.37 \\
\hline
\end{tabular}

Table (3)

Moment movement variables of the research sample performance for the skill of soccer kicking with the three methods

\begin{tabular}{|c|c|c|c|c|c|}
\hline $\begin{array}{l}\text { Body } \\
\text { parts }\end{array}$ & Movement variables & $\begin{array}{l}\text { Measurement } \\
\text { unit }\end{array}$ & $\begin{array}{l}\text { Whip } \\
\text { kick }\end{array}$ & $\begin{array}{l}\text { Rebound } \\
\text { kick }\end{array}$ & $\begin{array}{c}\text { Simple } \\
\text { kick }\end{array}$ \\
\hline \multirow{11}{*}{$\begin{array}{l}\text { Total } \\
\text { body }\end{array}$} & Horizontal Velocity of kicking Simple foot take off & Meter/ sec & 1 & 25.5 & 26.5 \\
\hline & $\begin{array}{l}\text { Angle of kicking foot ankle in the moment of kicking the } \\
\text { ball }\end{array}$ & Angular degree & 163 & 172 & 163 \\
\hline & $\begin{array}{c}\text { Horizontal Velocity of kicking Simple foot in the moment } \\
\text { of kicking the ball }\end{array}$ & Meter/ sec & 16 & 15 & 16.5 \\
\hline & $\begin{array}{l}\text { Vertical displacement of kicking Simple foot in the } \\
\text { moment of kicking the ball }\end{array}$ & Meter & 0.38 & 0.33 & 0.37 \\
\hline & $\begin{array}{c}\text { Broad angle of the pivot Simple foot in the moment of } \\
\text { kicking the ball }\end{array}$ & Angular degree & 16 & 16.5 & -3 \\
\hline & $\begin{array}{l}\text { Horizontal force of kicking foot in the moment of kicking } \\
\text { the ball }\end{array}$ & newton & 202.5 & 205 & 202.5 \\
\hline & $\begin{array}{l}\text { The Momentum for the kicking foot in the moment of } \\
\text { kicking the ball }\end{array}$ & $\mathrm{kg} / \mathrm{m} / \mathrm{sec}$ & 4.05 & 8.10 & 4.05 \\
\hline & $\begin{array}{l}\text { Horizontal kinetic energy for the kicking foot in the } \\
\text { moment of kicking the ball }\end{array}$ & joule & 5.06 & 10.12 & 5.06 \\
\hline & $\begin{array}{c}\text { Internal angle of kicking leg knee in the moment of } \\
\text { kicking the ball }\end{array}$ & Angular degree & 180 & 172 & 161 \\
\hline & $\begin{array}{l}\text { Internal angle of pivot leg knee in the moment of kicking } \\
\text { the ball }\end{array}$ & Angular degree & 168 & 153 & 157 \\
\hline & $\begin{array}{l}\text { Horizontal displacement for point of pelvis of kicking } \\
\text { leg in the moment of kicking the ball }\end{array}$ & Meter & 0.02 & 0.1 & 0.08 \\
\hline
\end{tabular}




\begin{tabular}{|c|c|c|c|c|c|}
\hline & $\begin{array}{l}\text { Horizontal Velocity for point of pelvis of kicking leg in } \\
\text { the moment of kicking the ball } \\
\text { Heighten of body gravity center in the moment of kicking } \\
\text { the ball }\end{array}$ & $\begin{array}{c}\text { Meter/ sec } \\
\text { Meter }\end{array}$ & $\begin{array}{c}3 \\
1.07\end{array}$ & $\begin{array}{c}5 \\
1.01\end{array}$ & $\begin{array}{c}4 \\
1.04\end{array}$ \\
\hline \multirow{6}{*}{ The ball } & Heighten of ball take off point & Angular degree & 0.51 & 0.11 & 0.37 \\
\hline & Horizontal angle of ball take off & Meter & 46 & 45 & 53 \\
\hline & Broad angle of ball take off & Angular degree & 9 & 14 & 17 \\
\hline & Horizontal Velocity of ball take off & Meter/ sec & 47.5 & 45.5 & 46 \\
\hline & Horizontal distance of ball take off & Meter & 61 & 57 & 54 \\
\hline & .The competency of ball direction & (18) max .degree & 15 & 9 & 7 \\
\hline
\end{tabular}

Table (4)

The criterion to select soccer goalkeeper according to the basic general movement variables for the quantitative Kinetic analysis for skill performance of the moved and flying long kick of soccer (which prepared from goalkeeper)

\begin{tabular}{|c|c|c|c|c|c|}
\hline \multicolumn{3}{|c|}{ The basic movement variables } & \multirow{2}{*}{$\begin{array}{c}\begin{array}{c}\text { The best } \\
\text { trial }\end{array} \\
62\end{array}$} & \multirow{2}{*}{$\begin{array}{c}\begin{array}{c}\text { Mean of total } \\
\text { trials }\end{array} \\
57\end{array}$} & \multirow{2}{*}{$\begin{array}{c}\begin{array}{c}\text { Mean square } \\
\text { error }\end{array} \\
0,59\end{array}$} \\
\hline & The results of the & Horizontal distance of ball flying (meter) & & & \\
\hline 1 & $\begin{array}{l}\text { performance of the ball } \\
\text { kick }\end{array}$ & $\begin{array}{l}\text { The competency of ball direction (degree } \\
\text { ) }\end{array}$ & 16 & 10 & 0,71 \\
\hline \multirow{6}{*}{2} & \multirow{6}{*}{$\begin{array}{l}\text { The results of the } \\
\text { performance of the ball } \\
\text { kick }\end{array}$} & $\begin{array}{l}\text { Horizontal angle of ball take off } \\
\qquad(\mathrm{m} / \mathrm{second})\end{array}$ & 49 & 46 & 0,93 \\
\hline & & $\begin{array}{l}\text { Horizontal velocity of ball take off } \\
\text { (Angle degree) }\end{array}$ & 45 & 48 & 0.99 \\
\hline & & Heighten of ball take off point (meter) & 0.50 & 0.44 & 1.16 \\
\hline & & Board angle of ball take off (angle dgree) & 7 & 13 & 1.43 \\
\hline & & $\begin{array}{l}\text { Total time of kinetic performance for the } \\
\text { skill (second) }\end{array}$ & 0.34 & 0.37 & 1.75 \\
\hline & & $\begin{array}{l}\text { Heighten of body gravity center in the } \\
\text { moment of kicking the ball (meter). }\end{array}$ & 1.07 & 1.04 & 1.82 \\
\hline
\end{tabular}

Figure (1)

Methods of performing the three kicks (under research)

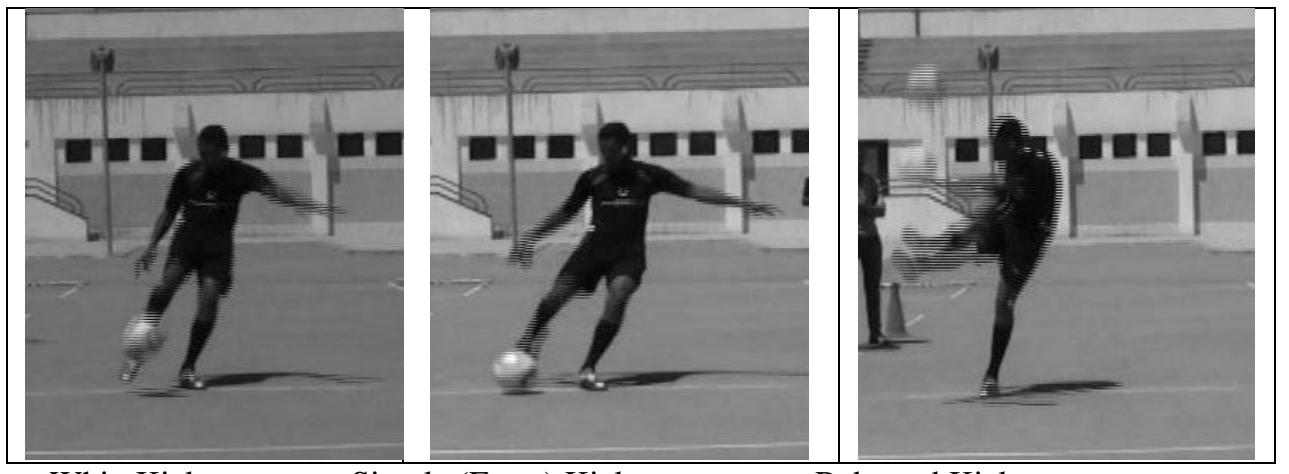

Whip Kick

Simple (Front) Kick

Rebound Kick 
Figure (2)

Time of research sample performance for the skill of kicking moving ball with the three method

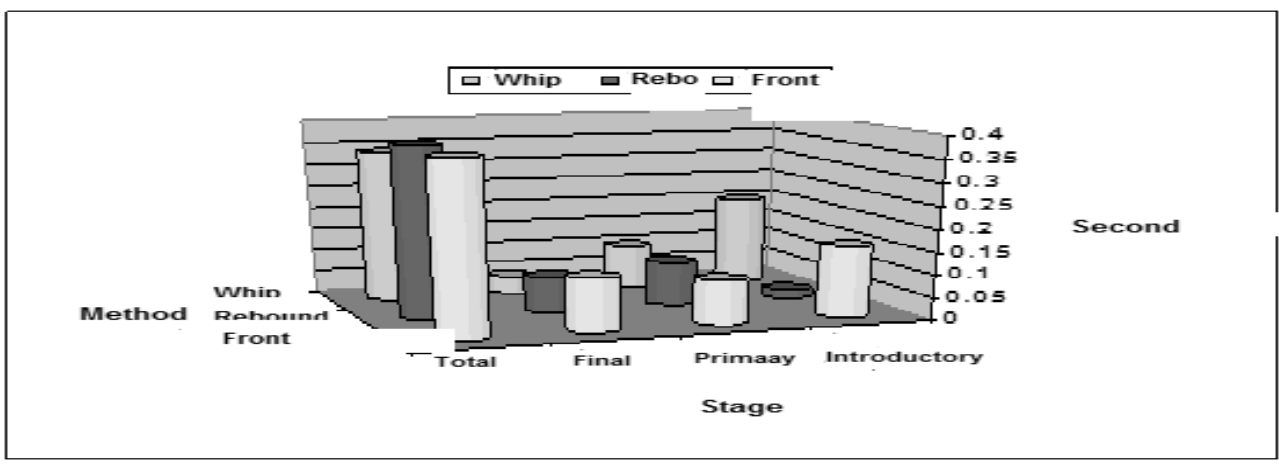

Figure (3)

Height of ball take off in the three performance methods of the research sample

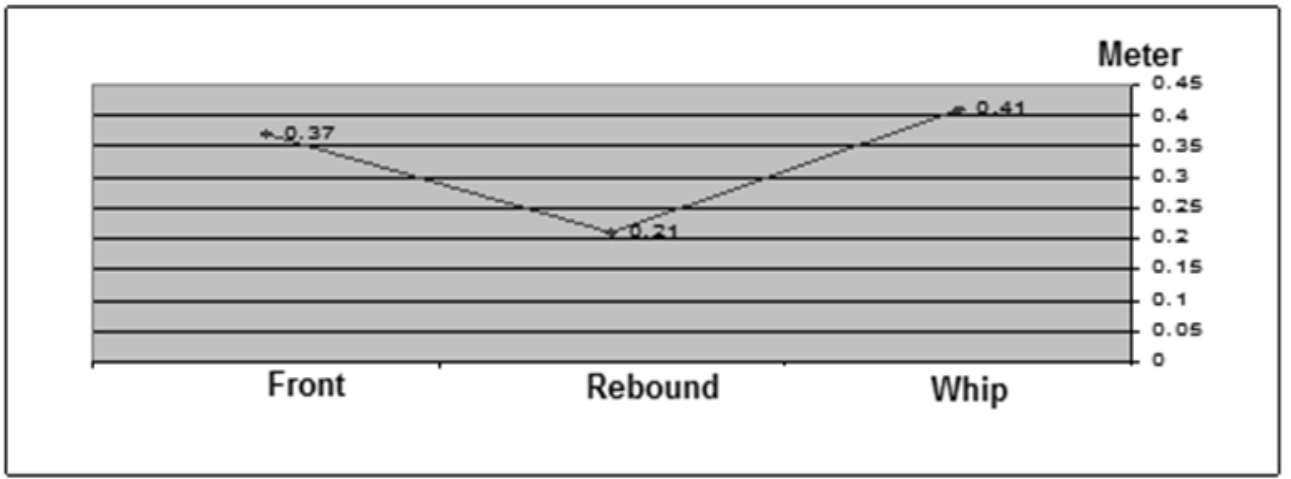

It is shown from (figure 2) that the least time for performing the skill of moving kicking for soccer goalkeepers (the research sample) was in the method of whip kick, where it was (0.34) seconds, then equally in both rebound and simple methods where it was (0.38) seconds it elucidates also the shortening of preparatory stage (0.16) and length of the final stage in which its time was (0.12) seconds in the simple kick than the other kicks. It is noticed here the equality of basic stage time in the three kicks for the research sample where it was $(0.10)$ seconds .

Table (2) shows us, that the highest linear displacement for kick front foot point realsed in the whip kick reaching (2.03) meter where the highest vertical displacement was in the simple kick that was (1.06) meter however the highest broad displacement was achieved in the whip kick of (0.99) meter .

Table (2) shows that for the point of kicking front foot, it reached the highest vertical intermediate Velocity in the rebound kick where it was $(17,00)$ meter / second ,While the highest vertical Velocity was in the simple kick of (8.70) meter / second. Whereas it was the highest intermediate broad Velocity in the whip kick of (4.95) meter/ second.

the whip kick achieved a score value in the variable of ball take off point heighten was $(0.51)$, the horizontal angle of ball take off (65), the broad angle of ball take off (83), the horizontal Velocity of ball take off (47.5) $\mathrm{m} / \mathrm{sec}$., the horizontal distance of ball flight (61) meter, the competency of ball direction (15) from (18) degree .

It is clear from Table (4) that the basis of the selection of football goalkeepers according to the Range between the best trial and the Mean of the total trial or the squared mean error between the trials for the main kinetic variables resulting of kinetic analysis of the skill of the long kick of the flying of ball (prepared by the goalkeeper for himself) were represented in the basic kinetic variables relating of the results and characteristics of kick performance. The squared mean error for these bases has been ranged from( 0.59 -1.82), the best of which is the value of the horizontal distance variables of the flight of ball (0.59) The competency of ball direction (0.71), the horizontal velocity of the ball (0.93), the horizontal angle of the ball (0.99) the 
Heighten of ball take off (1.16), the lowest value was the variable of Heighten of body gravity center in the moment of kicking the ball (1.82), the total time to perform the skill of (1.75), then the angle of the starting point of the ball (1.43)and the best one achieved by the whip method .

\section{Disscussing}

The little time for performing the skill of moving kicking for soccer goalkeepers. the research sample - in the method of whip kick, then equally in both rebound and simple methods, that due to shortening of the final stage for the whip kick through which the swinging of the kick leg isn't done for a high vertical displacement like the two other methods and most of its movement was in the horizontal direction (Ali, Abdel Basser, 2007, p. 370) indicates that "it is necessary to analyze projectile Velocity to two vehicle, one is vertical and the other is horizontal to understand and operating the required movement performance ".

The highest linear displacement for kick front foot point achieved in the whip kick where. the highest vertical displacement in the simple kick and the highest broad displacement in the whip kick, due to to the lengthen of rotation arch of front kick foot forward and outside in the whip method, then shortening it before the end of the kick basic stage for cumulating the biggest possible torque in kicking. ( Hosaam El Deen, 1993, p. 276 ) argues that "reducing turning radius of the body during its rotation in the decisive moments leads to increasing its Velocity and vice versa in the limits of the right angle momentum" .

As for the point of kicking front foot, the highest vertical intermediate Velocity was in the rebound kick ,the highest vertical Velocity was in the simple kick, and the highest broad intermediate Velocity was in the whip kick, that due to the shortness of horizontal and vertical displacement in the rebound kick and the positive effect of the movement transfer from the trunk to pelvis of the kicking foot knee during its swinging in the broad direction .(El Awaady \& Labib, 2003, p33) argued that if the duty of movement is the instrument, the movement transfer is in the direction of the instrument that is from the trunk to the limbs i.e for the kicking leg. (El Sheik, 1982, p. 325) indicates that "it is necessary that Velocitys of all body parts centre gravity participating in the movement as far as possible are directed to the desired direction when arriving to its maximum Velocity". that the whip kick came in the first rank in horizontal distance for ball then the rebound kick and at last the simple one, which due to, that ball movement variables were the criterion in causing the horizontal distance in the three kicks where these variables represent a system with each other with particular rates and amounts, the best were in the whip method. "Abientano , Nanomy, Aki Jemy \& Sano, 2006, p. 953) indicate that "the leg force is an important thing for leg swinging Velocity in a quicker method, consequently a high Velocity of the ball" . (Sawsan, Amien, Sabry \& Raageb, 1979, p. 325-333 ) mentions that "the most important factors to acquire the biggest horizontal distance for the projectile are take off Velocity, take off angle, heighten of take off point".

Abdel Baseer Ali , Adel \& Abdel Baseer, Ehab. ( 2007) bio-mechanical analysis and integration between theory and application .Alexandria: Egyptian library.

Hosaam Eldeen, Talha. (1993) . biomechanics . theoretical and applied bases . Cairo : Dar El Feker ELAraby .

Alaawady, Sherif \& Labib , Omar . (2003) . a notebook of movement analysis. department of kinesiology . faculty of physical education. Minia university. Egypt .

Alshegk, Mohamed . (1992) . bio mechanics . Cairo : Dar El Maaref .

Tommy Apriantono, Hiroyuke, Yasuo ikegami ,Shinya Sano :The effect of muscle fatige on instep kicking kinetics and kinematics in association football Journal of Sport , Nagoya University , Nagoya ,Japan , Septamber, 2006.

Abdel Monem Sawsan , Amien Osam , Sabry Mohamed . \& Raageb Mohamed . (1977) . biomechanics in sport field . the first section . Cairo : Dar El Maaref .

The lower value of the squared mean error for most of the basic movement variables related to the results and characteristics of the long kick performance is due to the fact that these variables are the most important in achieving the mechanical goal of the long kick, which is the reaching the ball to the possible maximum horizontal distance with the Availability of accuracy in the fall of the ball in the best place to reach the opponent's goal in the least time, and therefore these variables are important foundations to choose the best performance of the long kick, which is an important basis in the selection of good goalkeeper because of their great importance in preparing many fast attacks to the goalkeeper team during the matches. 


\section{Conclusions}

- The time of performing the whip kick is the least where it was (0.34) sec., whereas it was in both the rebound and the simple kicks (0.38).

- The whip kick achieved the biggest horizontal distance of (61) meter, then the rebound kick of (57) meter, then the simple kick of (54) meter

- The whip kick surpassed in most movement variables of the ball following the rebound kick, then the simple kick.

- The criterion to select soccer goalkeeper according to the most basic kinetic variables for the quantitative Kinetic analysis of skill performance long kick for the moved and flying soccer (which prepared from goalkeeper) represented in horizontal distance of ball fling, the competency of ball direction, horizontal velocity of ball take of, horizontal angle of ball take off and Heiten of ball take off point .

\section{Recommendations}

- Teaching and developing more than method for performance of long kicks (under

- study) for the soccer goalkeepers and giving more priority in training on the whip kick then the rebound kick and simple kick .

- Selecting, teaching or training soccer goalkeepers on long kicks for that flied moved ball according to the Digital standards of the kinetic variables listed in the search.

- focusing on qualitative exercises specific for developing elements of muscular ability, velocity and kinetic flexibility of kicks (under study) especially whip kick

- Giving the biggest interest during training on kicks under research on movement variables of the ball representing in ball take off point heighten, the horizontal angle of ball take off , the broad angle of ball take off, the horizontal Velocity of ball take off and the horizontal distance of ball flight and competence of ball direction .

\section{References}

1- Abdel Baseer Ali , Adel \& Abdel Baseer, Ehab. ( 2007) . bio-mechanical analysis and integration between theory and application .Alexandria: Egyptian library.

2- Abdel Monem , Sawsan ., Amien , Osam ., Sabry , Mohamed . \& Raageb , Mohamed . (1977) . biomechanics in sport field . the first section . Cairo : Dar El Maaref .

3- Alaawady , Sherif \& Labib , Omar . (2003) . a notebook of movement analysis. department of kinesiology . faculty of physical education. Minia university. Egypt .

4- Albendary, Amr. (2013) . the effect of sport fatigue on biomechanics of lower limb of kicking in soccer, (unpublished master thesis) . faculty of physical education. El Mansoura university . Egypt .

5- Alen Kapidžić1, Tarik Huremović1,\& Alija Biberovic1. (2014) . Kinematic Analysis of the Instep Kick in Youth Soccer Players , Journal of Human Movements volume 42/2014, 81-90 DOI: 10.2478/hukin- 2014- 0063 Kinesiology Accepted for printing in Journal of Human Movements vol. 42/2014 on September 2014.

6- Alsayed , Mohamed \& Kamel ,Yahiaa . (2006) . an analytical study for attack tactical movements in the attack third based upon shooting opportunities in soccer . magazine of sport science. VOL . December. 2006.

7- Alshegk, Mohamed . (1992) . bio mechanics . Cairo : Dar El Maaref .

8- Atteya , Falaah . (2010) . analyzing and evaluating some biomechanical variables in performing the skill of soccer penalty kick . Al-Qadisiyah university for physical education sciences . tenthth volume.no.2. pp.238.2010.

9- Claudio A Casal1, Rubén Maneiro2, Toni Ardá2, José L Losada3 \& Antonio Rial4. (2016) . Analysis of Corner Kick Success in Elite Football, International Journal of Performance Analysis in Sport , 2015, 15, 430-451. April 2016 Football Study Guide.

10- Garry Gelady . (2014) . Evaluating the ability of goalkeepers in English Premier League football, de gruyter, doi 10.1515/jqas-2014-0004 jqas 2014; aop.

11- Hassan, Mohamed . (2002) . directing some biomechanical indicators for improving the performance of direct free kick in soccer . unpublished doctoral thesis . faculty of physical education for boys . Zaghazek university . Egypt .

12- Hassan, Mohamed . (1997) . biomechanical comparison between two methods of kicking with inside and front foot in soccer. (unpublished master thesis) . faculty of physical education for boys . Zaghazek university . Egypt . 
13- Hassanin , Mohamed . (1999) . measurement and evaluation in physical education . first section . edition 4. Cairo: Dar El Feker El Araby .

14- Hosaam Eldeen, Talha. (1993) . biomechanics . theoretical and applied bases . Cairo : Dar El Feker ELAraby .

15- Jeffrey K. Leela \& Donna M. G. Comissiong . (2009) . Modelling Football Penalty Kicks , The University of the West Indies, St. Augustine, Trinidad. (Received 7 February 2009; accepted 24 April 2009).

16- Kendra Alberts, Kyleah Bowder \& Kelsey Timmerman.(n.d) Movement Analysis of Kicking A Soccer

Ballhttp://www.youtube.com/watchv=HwKlulAThV0\& feature $=$ youtu.b

17- M. Harlev, S. J_uliusd_ottir, D. Pedersen, \& K. K. T. Thomsen . (2012) . Correlation analysis of ball Velocity, EMG and inverse dynamics calculated muscle forces in the swing leg during instep soccer kicks . Aalborg University . December 19, 2012.

18- Sam , Millar . (2004) . Kinematics of drop punt kicking in australian rules football - comparison of skilled and less skilled kicking . melbourne . australia . august . 2004.

19- Shael Brown. (n.d) . The Physics of Kicking a Soccer Ball . www.SeriousSoccer.net

20- T. Asai1, M. J. Carre' 2, T. Akatsuka3 \& S. J. Haake2. (2002) . The curve kick of a football I: impact with the foot, 2002 Blackwell Science Ltd - Sports Engineering (2002) 5, 183-192 . Faculty of Education, Yamagata University Koshirakawa, Yamagata-city, Yamagata 990-8560, Japan.

21- Takehi asai, Thomas Andersen, hiroyu Nunome \& Thorsten sterizing . (2010) . the biomechanic kiking in soocer : A Review, Journal of Sports Sciences · June 2010 .

22- Thorsten Sterzing . (2010) . Kicking in Soccer . Institute for Sports Science. Chemnitz University of Technology.Germany .

23- Tommy Apriantono, Hiroyuke, Yasuo ikegami ,Shinya Sano :The effect of muscle fatige on instep kicking kinetics and kinematics in association football Journal of Sport, Nagoya University, Nagoya ,Japan , Septamber, 2006. 